\title{
Padronização de um método para mensuração das tábuas ósseas vestibular e lingual dos maxilares na Tomografia Computadorizada de Feixe Cônico (Cone Beam)
}

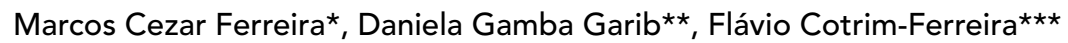

\begin{abstract}
Resumo
Introdução: a espessura das tábuas ósseas que recobrem os dentes por vestibular e lingual constitui um dos fatores limitantes da movimentação dentária. $\mathrm{O}$ avanço tecnológico em Imaginologia permitiu avaliar detalhadamente essas regiões anatômicas por meio da utilização da tomografia computadorizada de feixe cônico (TCFC). Objetivo: descrever e padronizar, pormenorizadamente, um método para mensuração das tábuas ósseas vestibular e lingual dos maxilares nas imagens de tomografia computadorizada de feixe cônico. Metodologia: a padronização digital da posição da imagem da face deve constituir o primeiro passo antes da seleção dos cortes de TCFC. Dois cortes axiais de cada maxilar foram empregados para a mensuração da espessura do osso alveolar vestibular e lingual. Utilizou-se como referência a junção cemento-esmalte dos primeiros molares permanentes, tanto na arcada superior quanto na inferior. Resultados: cortes axiais paralelos ao plano palatino foram indicados para avaliação quantitativa do osso alveolar na maxila. $\mathrm{Na}$ arcada inferior, os cortes axiais devem ser paralelos ao plano oclusal funcional. Conclusão: o método descrito apresenta reprodutibilidade para utilização em pesquisas, assim como para a avaliação clínica das repercussões periodontais da movimentação dentária, ao permitir a comparação de imagens pré e pós-tratamento.
\end{abstract}

Palavras-chave: Tomografia. Tomografia Computadorizada de Feixe Cônico Espiral. Ortodontia. Diagnóstico. Processo Alveolar.

\section{INTRODUÇÃO}

A relação entre o tratamento ortodôntico e a saúde periodontal sempre foi motivo de preocupação entre ortodontistas e periodontistas, quer pelos níveis de força aplicados, quer pela preocupação com o tecido periodontal inicial e final ${ }^{1,8,9,10,13}$.

Os efeitos periodontais ocasionados pela movimentação dentária, seja para tábua óssea vestibular ou lingual, ainda possuem poucas evidências científicas. Estudos realizados com essa finalidade,

* Aluno do programa de pós-graduação em Ortodontia (mestrado) na Universidade Cidade de São Paulo (UNICID). Professor do Curso de Especialização em Ortodontia do IOM/UNIG (RJ).Professor do Curso de Especialização em Ortodontia da ABO/ Niterói (RJ). Coordenador do Departamento de Ortodontia da Policlínica Geral do Rio de Janeiro.

** Professora doutora de Ortodontia no Hospital de Reabilitação de Anomalias Craniofaciais / Universidade de São Paulo (HRAC/USP-Bauru).

*** Professor associado de Ortodontia da UNICID. 
em macacos e cães, demonstraram que os movimentos para vestibular induzem deiscências ósseas e, em menor grau, recessões gengivais. O reposicionamento dentário em direção lingual pode ocasionar uma regeneração parcial da tábua óssea vestibular, com migração coronal da crista óssea vestibular ${ }^{3,12,14}$.

A maior parte da literatura acerca das repercussões periodontais do tratamento ortodôntico preocupou-se com a avaliação das cristas ósseas interproximais, principalmente em áreas de extrações. No geral, os estudos reportaram uma maior perda óssea alveolar nos grupos tratados ortodonticamente, principalmente em áreas de extração, mas com magnitude não relevante clinicamente. Ademais, existem diversas evidências de que os efeitos da movimentação dentária induzida podem se sobrepor à inflamação causada pelas bactérias, aumentando a velocidade de destruição periodontal. No entanto, os trabalhos avaliando o periodonto por vestibular ou lingual são mais escassos, talvez devido à impossibilidade de visualização dessas regiões em radiografias bidimensionais ${ }^{7}$. Contudo, com o advento da tomografia computadorizada, e mais ainda com a tomografia computadorizada de feixe cônico ${ }^{6}$ - que permite exames com doses significantemente menores de radiação -, atualmente é possível realizar avaliações quantitativas e qualitativas das tábuas ósseas vestibular e lingual. Estudos com tomografia computadorizada apontaram que quanto mais delgada a tábua óssea ao início do tratamento, maiores são as chances de deiscências durante os movimentos de giroversão ou vestibularização ${ }^{4,5,11}$.

Dessa maneira, a presença e a espessura da tábua óssea vestibular e lingual passam a constituir fator limitante da movimentação dentária e deveriam ser consideradas no planejamento ortodôntico. Ademais, para fins de pesquisa, faz-se necessário criar uma padronização pormenorizada do método para mensuração das tábuas ósseas vestibular e lingual dos maxilares na tomografia computadorizada de feixe cônico (Cone Beam), o que constitui o objetivo primordial do presente trabalho.

\section{MATERIAL E MÉTODOS}

Será descrita, detalhadamente e passo-a-passo, uma proposta de metodologia para avaliação quantitativa das tábuas ósseas vestibular e lingual dos dentes superiores e inferiores. Os passos metodológicos foram adequados para o tomógrafo i-CAT (www.imagingsciences.com) e para o programa $\mathrm{Ne}$ moScan (Nemotec, Madrid/Espanha).

\section{Obtenção das imagens}

Antes da tomada do exame, o tomógrafo deve ser ajustado para funcionar segundo as seguintes especificações: $120 \mathrm{KvP}, 8 \mathrm{~mA}$ e tempo de exposição de 20 segundos. Os pacientes devem ser orientados a permanecer sentados no aparelho, com a cabeça posicionada com o plano de Frankfurt paralelo ao solo, e plano sagital mediano perpendicular ao solo (Fig. 1)

Para englobar a região dentoalveolar da maxila e da mandíbula, assim como os planos de referência utilizados nessa metodologia, o protocolo de aquisição de imagem utilizado foi o exame da "face" com extensão cefalocaudal de $13 \mathrm{~cm}$, ou "face extendida" com $22 \mathrm{~cm}$ para pacientes com a face maior. A espessura do voxel - e, portanto, dos cortes axiais - pode corresponder a 0,3 ou $0,4 \mathrm{~mm}$.

As imagens da tomografia computadorizada cone beam são adquiridas em formato DICOM (Digital Imaging and Communication in Medicine). No formato DICOM, as imagens adquiridas em quaisquer tomógrafos, independentemente do processo de aquisição (single, multislice, feixe cônico) podem ser lidas em softwares para imagens volumétricas. As imagens originais em formato DICOM apresentam uma chave de segurança, ou número associado, que impossibilita a sua modificação e lhe provê valor legal (Fig. 2).

\section{Padronização do posicionamento das imagens}

Após copiar o arquivo do exame para um computador convencional, utilizando o software Nemoscan, padroniza-se a posição das imagens antes de selecionar os cortes para mensuração. 

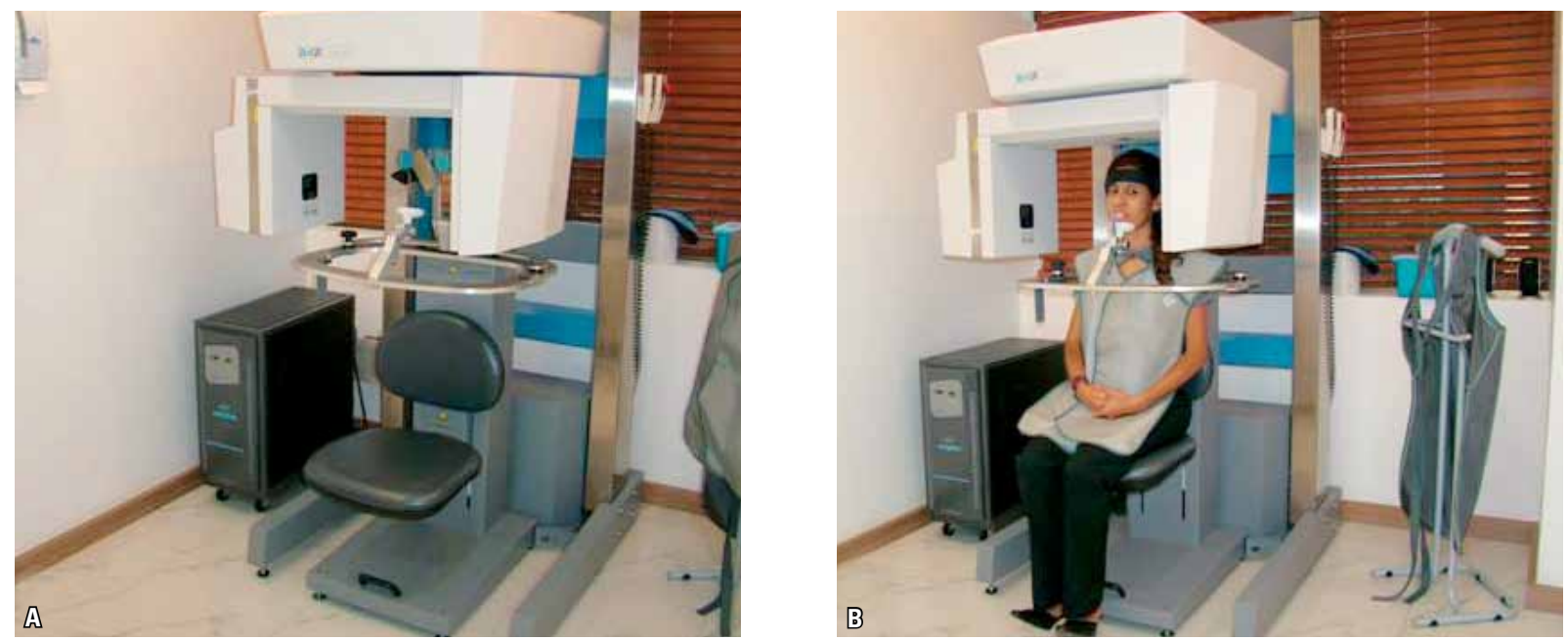

FIGURA 1 - A) i-Cat, aparelho de tomografia computadorizada cone beam utilizado na realização deste trabalho. B) Paciente com a cabeça posicionada com o plano de Frankfurt paralelo ao solo e plano sagital mediano perpendicular ao solo.

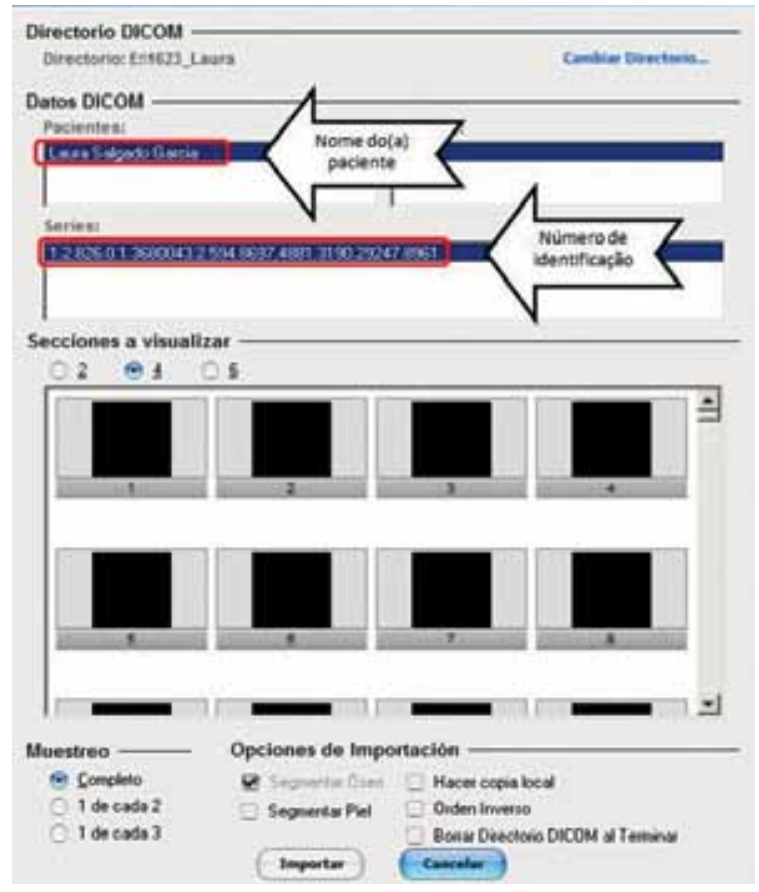

FIGURA 2 - Janela do programa Nemoscan, onde se visualizam cada um dos cortes axiais originais da tomada de tomografia computadorizada, para que sejam importados e manipulados no software.

A visualização dos cortes nas três dimensões do espaço (cortes axiais, sagitais e coronais), como mostra a figura 3, é denominada reconstrução multiplanar. Nessa tela é possível realizar a seleção dos cortes, ou seja, em qual profundidade ou qual estrutura se deseja visualizar, além de permitir a rotação das imagens para que possamos coincidi-la com as linhas de referência, conforme demonstrado na figuras 4 e 5 .

As referências para padronizar a posição das imagens devem ser escolhidas nos três planos. A referência escolhida para padronizar os planos axial e sagital foi a linha biespinhal, fazendoa coincidir com os planos vertical e horizontal, respectivamente (Fig. 6, 7). A referência adotada para padronizar o plano coronal foi a linha entre os pontos infraorbitários, denominada de linha infraorbitária (Fig. 8), concluindo assim o posicionamento das imagens nos três planos do espaço (Fig. 9). Quando a padronização da posição cabeça é realizada utilizando-se a imagem em $3 \mathrm{D}$, em vez dos cortes multiplanares, como no programa Dolphin 3D (Dolphin Imaging and Management Solutions, Chatsworth, CA, EUA), pode-se utilizar o plano de Frankfurt como referência horizontal tanto na vista lateral direita quanto esquerda, e o plano infraorbitário na vista frontal da face.

\section{Seleção das imagens para mensuração}

Para a maxila, primeiramente selecionou-se, dentre os cortes axiais paralelos ao plano palatino (Fig. 10), o corte onde pudesse ser visualizada a 


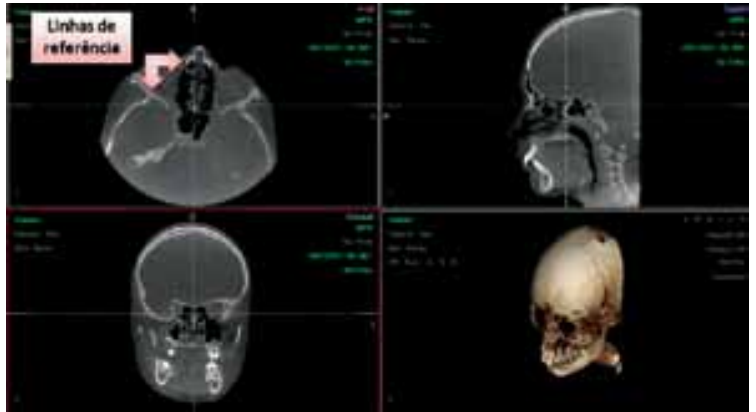

FIGURA 3 - Reconstrução multiplanar mostrando as linhas de referência horizontal e vertical presentes nos três planos (axial, sagital e coronal).
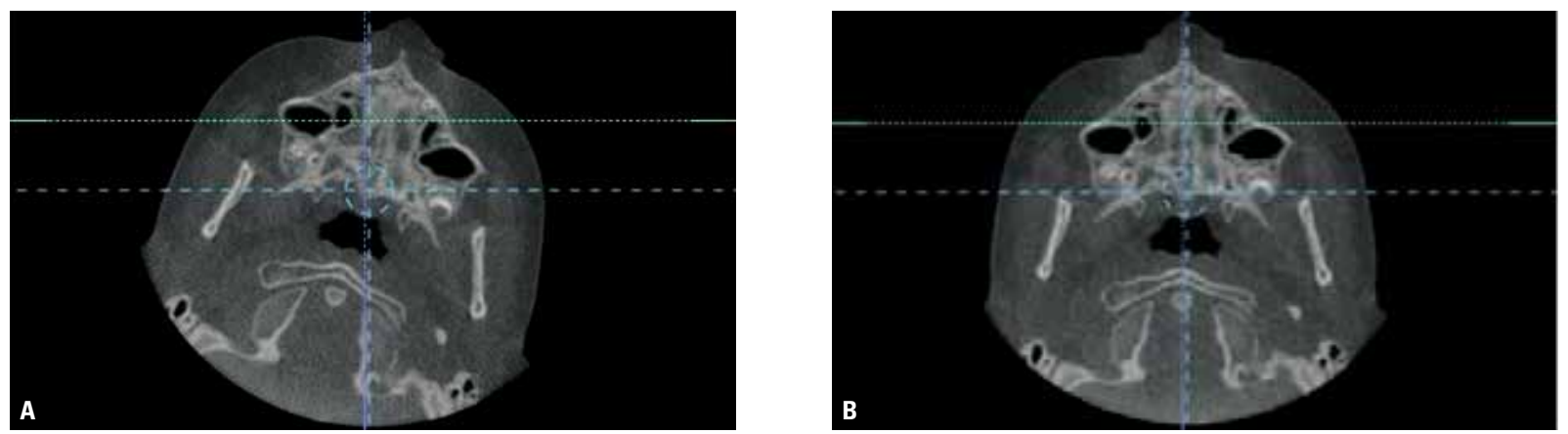

FIGURA 5 - Rotação da imagem axial, fazendo coincidir a linha biespinhal com a linha de referência vertical. Note que, se houve erro no posicionamento da cabeça do paciente durante a tomada tomográfica, essa discrepância pode ser corrigida nessa fase.

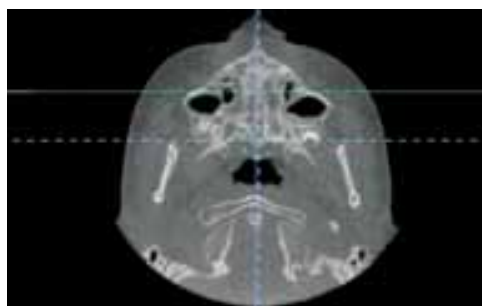

FIGURA 6 - Padronização do corte axial, fazendo coincidir a linha biespinhal com a linha de orientação vertical.

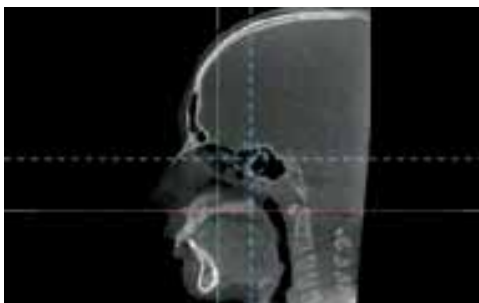

FIGURA 7 - Corte sagital, fazendo coincidir a linha biespinhal com a linha de orientação horizontal.

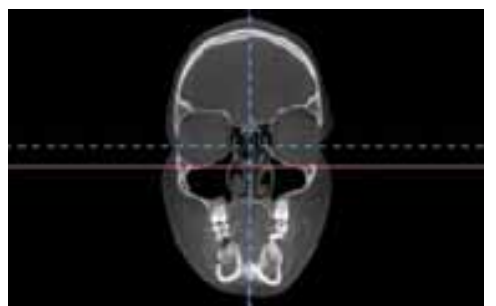

FIGURA 8 - Corte coronal, fazendo coincidir a linha infraorbitária com a linha de orientação horizontal (em rosa)

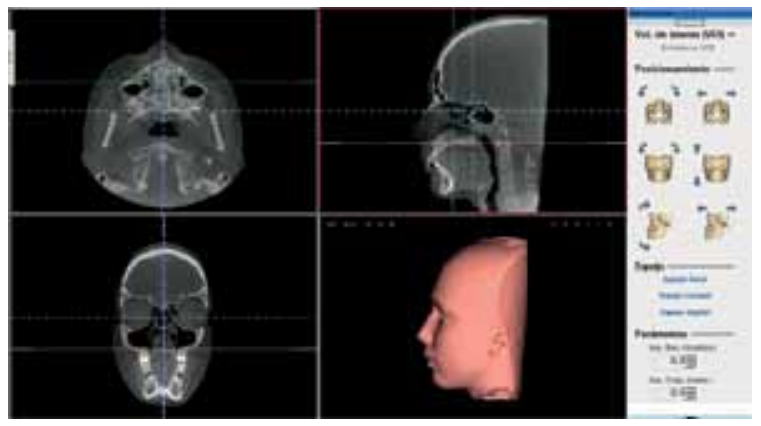

FIGURA 9 - Vista final do posicionamento tridimensional das imagens do paciente.

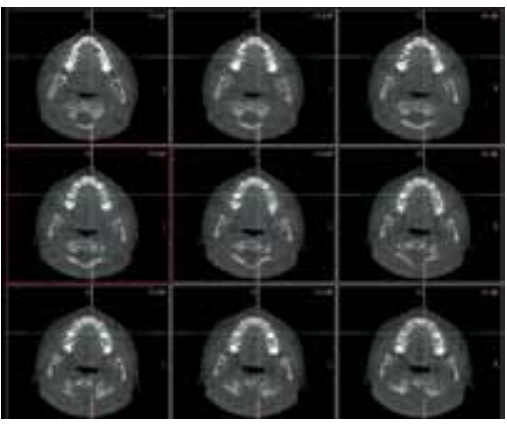

FIGURA 10 - Cortes axiais da maxila. 


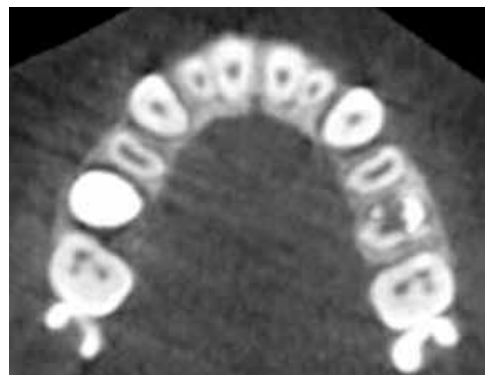

FIGURA 11 - Corte superior selecionado como referência, passando pela junção amelocementária da porção distovestibular do primeiro molar superior direito.

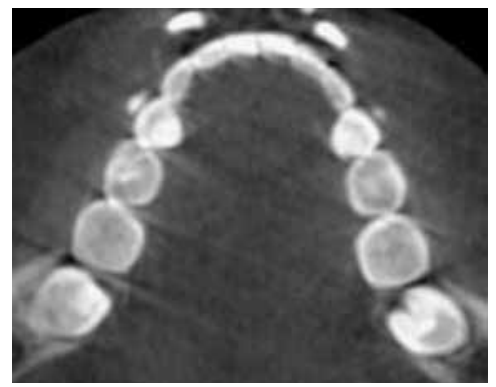

FIGURA 14 - Corte inferior selecionado como referência, passando pela junção amelocementária da porção distovestibular do primeiro molar inferior direito.

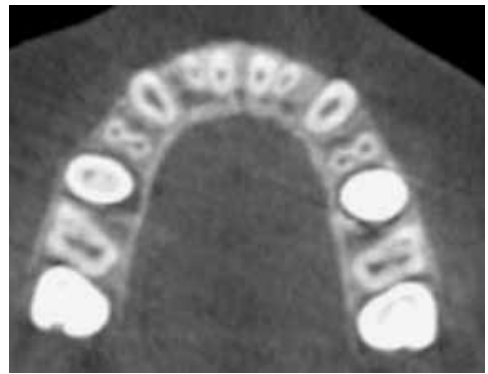

FIGURA 12 - Corte axial passando a 3,0mm da junção amelocementária do primeiro molar superior direito.

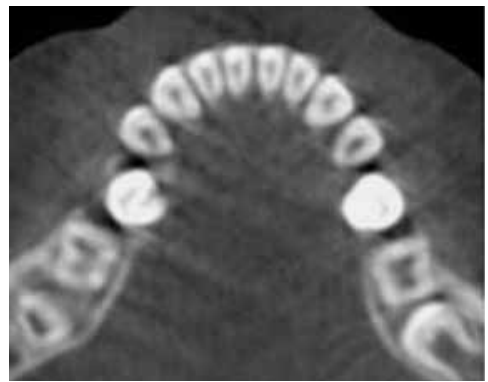

FIGURA 15 - Corte axial passando a 4,0mm da junção amelocementária do primeiro molar inferior direito.

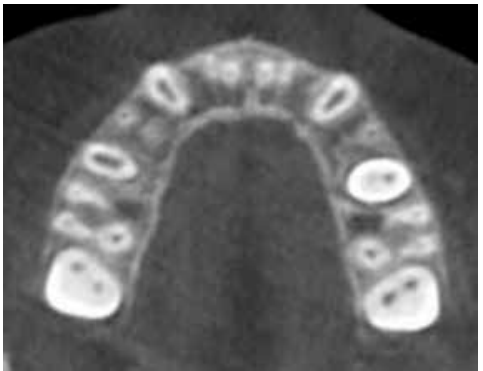

FIGURA 13 - Corte axial passando a 6,0mm da junção amelocementária do primeiro molar superior direito.

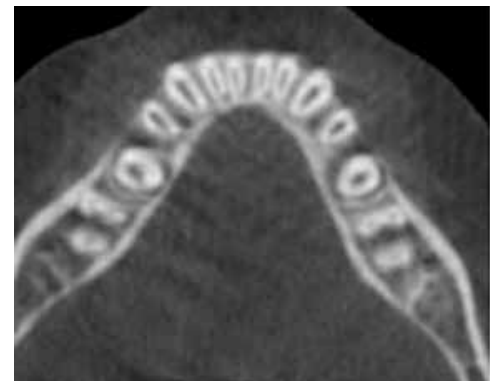

FIGURA 16 - Corte axial passando a 8,0mm da junção amelocementária do primeiro molar superior direito. junção amelocementária da porção distovestibular do primeiro molar superior direito (Fig. 11). A partir desse corte axial, selecionaram-se dois cortes axiais passando a 3,0 e 6,0 mm apicalmente à junção amelocementária, respectivamente ilustrados nas figuras 12 e 13.

Para a mandíbula, selecionaram-se cortes axiais paralelos ao plano oclusal funcional. Para tanto, procedeu-se ao reposicionamento da imagem da cabeça no software, girando-a para trás na magnitude equivalente ao ângulo formado entre o plano palatino (ENA-ENP) e o plano oclusal funcional. O plano oclusal refere-se a uma linha que passa pelo ponto de contato interoclusal mais distal dos primeiros molares e pelo ponto médio da sobremordida dos caninos. O ângulo PP.PO assume valores distintos para os diferentes tipos faciais (hipodivergente, mesodivergente e hiperdivergente) ${ }^{3}$. Após a mensuração desse ângulo na imagem da telerradiografia em norma lateral, reconstruída a partir da TCFC, a imagem da cabeça deve ser girada para trás o equivalente ao valor de correção do ângulo PP.PO, de modo que o plano oclusal funcional fique paralelo ao plano dos cortes axiais. Executa-se, então, o corte axial passando pela junção amelocementária da porção distovestibular do primeiro molar inferior direito (Fig. 14). Utilizando-se esse corte como referência, selecionaram-se dois cortes axiais passando a 4,0 e $8,0 \mathrm{~mm}$ da junção amelocementária referida, ilustrados, respectivamente, nas figuras 15 e 16 .

\section{Mensuração das imagens}

As medidas podem ser realizadas por vestibular e lingual pelo método digital. A partir do corte axial selecionado, executamos uma ampliação para facilitar a visualização do local desejado (Fig. 17). As mensurações da tábua óssea vestibular são realizadas em milímetros a partir do limite vestibular do contorno radicular até a porção mais 

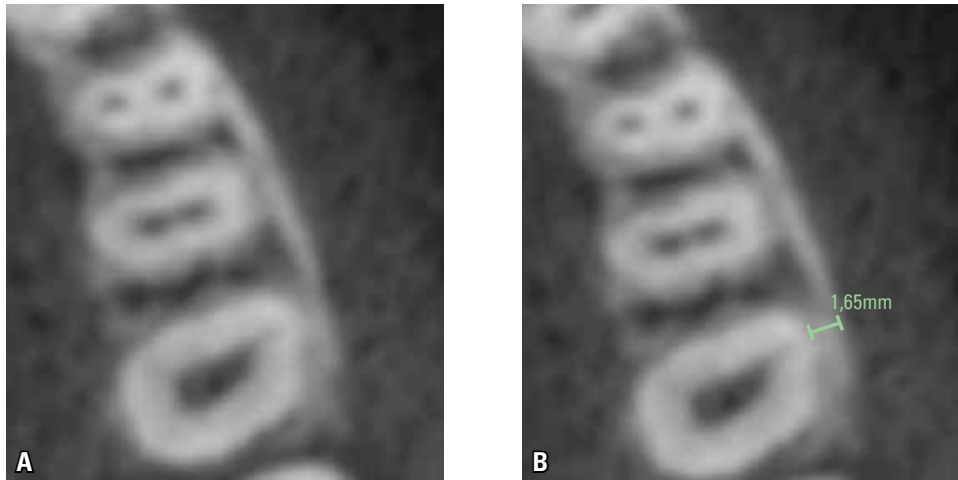

FIGURA 17 - Imagem ampliada para facilitar a mensuração $(\mathbf{A})$ e com a medida já executada (B).

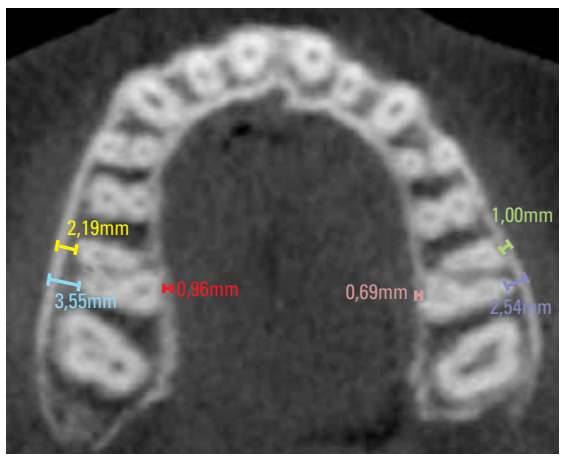

FIGURA 18 - Medidas executadas no próprio programa, indicando o valor em milímetros da espessura das tábuas ósseas vestibular e lingual. externa da cortical óssea, perpendicularmente ao contorno da arcada dentária. A mensuração da tábua óssea lingual estende-se do limite lingual do contorno radicular até a superfície externa da tábua óssea lingual (Fig. 18).

\section{CONCLUSÃO}

Portanto, a partir de uma metodologia padronizada, possibilita-se a avaliação detalhada da espessura das tábuas ósseas vestibular e lingual. Estudos conduzidos com essa metodologia poderão avaliar os riscos assumidos quando executamos movimentos dentários para lingual ou vestibular, além de nos permitir avaliar os limites da movimentação ortodôntica. O movimento dentário mesiodistal para regiões de osso atrófico também poderá ser avaliado mediante essa metodologia. Enfatiza-se que o método de avaliação proposto nesse trabalho volta-se principalmente para as pesquisas. Com o intento de possibilitar que $o$ clínico avalie as tábuas ósseas vestibular e lingual, a análise visual dos cortes axiais e parassagitais sequenciais torna-se suficiente para denunciar os locais com espessura crítica de osso alveolar. No entanto, uma avaliação numérica precisa pode ser realizada comparando-se os exames pré e pós-tratamento de casos clínicos específicos com o auxílio desse método.
Enviado em: julho de 2009 Revisado e aceito: novembro de 2009 


\title{
Methodology standardization for measuring buccal and lingual alveolar bone plates using Cone Beam Computed Tomography
}

\begin{abstract}
Introduction: The thickness of the buccal and lingual bone plates constitutes one of the limiting factors of the orthodontic movement. The imaging technology has permitted the evaluation of this anatomical region, by means of cone beam computed tomography. Purpose: To describe and standardize, in details, a method for measuring the buccal and lingual bone plate thickness in CBCT images. Methodology: Digital standardization of face image should constitute the first step before the selection of CBCT slices. Two axial sections of each jaw were used for measuring the thickness of buccal and lingual bone plates. The cemento-enamel junction of the first permanent molars was used as a reference, both in the upper and lower arches. Results: Axial sections parallel to the palatine plane were recommended for quantitative evaluation of the alveolar bone plate in the maxilla. In the mandibular arch, the axial sections should be parallel to the functional occlusal plane. Conclusion: The method described shows reproducibility for evaluating the periodontal effects of tooth movement for clinical or researching purposes, permitting the comparison between pre and post-treatment images.
\end{abstract}

Keywords: Tomography. Cone-Beam Computed Tomography. Orthodontics. Diagnosis. Alveolar process.

\section{REFERÊNCIAS}

1. Boyd RL, Leggott PJ, Quinn RS, Eakle WS, Chambers D. Periodontal implications of orthodontic treatment in adults with reduced or normal periodontal tissues versus those of adolescents. Am J Orthod Dentofacial Orthop. 1989 Sep;96(3):191-8

2. Cavalcanti MGP, Sales MAO. Tomografia computadorizada. In Cavalcanti MGP. Diagnóstico por imagem da face. São Paulo: ed. Santos; 2008. cap. 1: 3-43

3. Engelking G, Zachrisson BU. Effects of incisor repositioning on monkey periodontium after expansion through the cortical plate. Am J Orthod. 1982 Jul;82(1):23-32.

4. Fuhrmann R. Three-dimensional evaluation of periodontal remodeling during orthodontic treatment. J Orofac Orthop. 1996 Aug;57(4):224-37.

5. Garib DG. Efeitos dentoesqueléticos e periodontais da expansão rápida da maxila com os aparelhos dentomucossuportado e dentossuportado: avaliação por meio da tomografia computadorizada. [Tese] Bauru (SP): Faculdade de Odontologia da USP; 2003.

6. Garib DG, Raymundo Jr R, Raymundo MV, Raymundo DV, Ferreira SN. Tomografia computadorizada de feixe cônico (Cone beam): entendendo este novo método de diagnóstico por imagem com promissora aplicabilidade na Ortodontia. Rev Dental Press Ortod Ortop Facial. 2007 mar-abr;12(2): 139-56.

7. Martins PP, Garib DG, Greghi SLA, Henriques JFC. Avaliação periodontal dos incisivos inferiores em pacientes tratados ortodonticamente com extração de quatro pré-molares. Rev Fac Odontol Bauru.2002;10(4):245-51.
8. Newman GV, Goldman MJ, Newman RA. Mucogingival orthodontic and periodontal problems. Am J Orthod Dentofacial Orthop. 1994 Apr;105(4):321-7.

9. Ong MA, Wang HL, Smith FN. Interrelationship between periodontics and adult orthodontic. J Clin Periodontol. 1998 Apr;25(4):271-7.

10. Rygh P, Bowling K, Hovlandsdal L, Williams S. Activation of the vascular system: a main mediator of periodontal fiber remodeling in orthodontic tooth movement. Am J Orthod. 1986 Jun;89(6):453-68.

11. Rungcharassaeng K, Caruso JM, Kan JY, Kim J, Taylor G. Factors affecting buccal bone changes of maxillary posterior teeth after rapid maxillary expansion. Am J Orthod Dentofacial Orthop. 2007 Oct;132(4):428.e1-8

12. Steiner GG, Pearson JK, Ainamo J. Changes of the marginal periodontium as a result of labial tooth movement in monkeys. J Periodontol. 1981 Jun;52(6):314-20.

13. Tanne K, Sakuda M, Burstone CJ. Three-dimensional finite element analysis for stress in the periodontal tissue by orthodontic forces. Am J Orthod Dentofacial Orthop. 1987 Dec;92(6):499-505.

14. Thilander B, Nyman S, Karring T, Magnusson I. Bone regeneration in alveolar bone dehiscences related to orthodontic tooth movements. Eur J Orthod. 1983 May;5(2):105-14.
Endereço para correspondência

Marcos Cezar Ferreira

Rua Malibú, 260 apto 205/Bloco I - Barra da Tijuca

CEP: 22.793-295 - Rio de Janeiro / RJ

E-mail: drmarcos_iom@yahoo.com.br 